\title{
ESTUDO SOBRE A PRODUTIVIDADE DE FEIJÃO CAUPI "VERDE" CONSORCIADO COM MILHO EM FUNÇÃO DA COLHEITA PARCELADA DAS VAGENS
}

Nerton da Penha Filho $^{1 *}$, Laura Leopoudina Sousa ${ }^{2}$, Tainá Macêdo dos Santos ${ }^{2}$, Wíctor Állyson Dias Rodrigues ${ }^{2}$, Felipe Thomaz da Camara ${ }^{3}$

1 Graduando em Engenharia Agronômica da Universidade Federal do Cariri (nerton.filho96@hotmail.com), Crato-Brasil;

2 Graduando em Engenharia Agronômica, Universidade Federal do Cariri;

3 Dr., Prof. Adjunto CCAB, Universidade Federal do Cariri.

Recebido em: 15/04/2017 - Aprovado em: 22/07/2017 - Publicado em: 31/07/2017 DOI: 10.18677/Agrarian_Academy_2017a24

\begin{abstract}
O feijão caupi (Vigna unguiculata (L.) Walp) é uma das culturas mais importantes das regiões Norte e Nordeste, nessas regiões geralmente é cultivado em sistema de consócio com o milho (Zea Mays L.). Foi realizado um experimento na área experimental do Centro de Ciências Agrárias e da Biodiversidade (CCAB) da Universidade Federal do Cariri (UFCA), com o objetivo de avaliar a produtividade de feijão caupi em vagens e grãos verdes em função dos sistemas de consórcio com o milho e da colheita parcelada do feijão. O delineamento experimental utilizado foi em blocos casualizados em esquema fatorial $5 \times 4$, constando de quatro repetições. 0 primeiro fator analisado foi o sistema de consórcio do feijão com o milho ( $\mathrm{C} 1, \mathrm{C} 2$, C3, C4 e C5) e o segundo foi a colheita parcelada do feijão (1를 $2^{a}$, $3^{\underline{a}}$ e $4^{\underline{a}}$ colheita). As variáveis analisadas foram Número de Grãos por Vagem (NG/V), Número de Vagens por Planta (NV/P) e Comprimento da Vagem (CV), Massa de 100 Grãos (M100G), a Produtividade de Vagens Verdes (PVV) e a Produtividade de Grãos Verdes (PGV). No consórcio, não houve diferença estatística para NG/V e M100G, já em NV/P e CV o sistema de consórcio C3 obteve as melhores médias. Para colheita parcelada, houve diferença estatística em todos os resultados. Conclui-se que o C3 e C5 apresentaram os melhores resultados de produção do feijão caupi consorciado com o milho e as colheitas 3 e 4, realizadas aos 77 e 85 dias após a semeadura, respectivamente, apresentaram os melhores rendimentos produtivos.
\end{abstract}

RESUMO

PALAVRAS-CHAVE: Grãos verdes; produção; vagens verdes.

\section{STUDY ON THE “GREEN” COWPEA PRODUCTIVITY INTERCROPPED WITH MAIZE IN FUNCTION OF PARCELED HARVEST OF PODS}

\section{ABSTRACT}

Cowpea (Vigna unguiculata (L.) Walp or string beans is one of the most important cultures of the North and Northeast regions, in these regions, usually, is cultivated in an intercrop with corn (Zea Mays L.). It was realized an experiment at the experimental area of the Center of Agricultural Science and Biodiversity from the Federal University of Cariri (UFCA), with the objective to evaluate cowpea productivity in green pods and grains in function of the intercrop systems with corn AGRARIAN ACADEMY, Centro Científico Conhecer - Goiânia, v.4, n.7; p.246 2017 
and the split bean harvest. The design was in randomized blocks in a factorial scheme $5 \times 4$, consisting of four repetitions. The first factor analyzed was the intercrop systems of cowpea and corn (c1, C2, C3, C4 and C5) and the second one was split bean harvest $\left(1^{\text {st }}, 2^{\text {nd }}, 3^{\text {rd }}\right.$ and $4^{\text {th }}$ harvest $)$. The analyzed variables were Number of Grains per Pots (NG/V), Number of Pots per Plant (NV/P), Pots Length (CV), Weight of 100 Grains (M100G), Green Pods Productivity (PVV) and Green Grains Productivity (PGV). At the intercrop, there was not statistical difference to NG/V and M100G, already for NV/P and CV the intercrop system C3 obtained the best average. For harvesting, there was statistical difference in all results. It was concluded that the C3 and C5 showed the best results of cowpea production intercropped with corn and the harvests 3 and 4, realized at 77 and 85 days after seeding, respectively, presented the best productive yield

KEYWORDS: Green grains; production; green pots.

\section{INTRODUÇÃO}

Vigna unguiculata (L.) Walp, popularmente conhecido como feijão caupi ou feijão de corda é uma das culturas mais importantes das regiões Norte e Nordeste, o seu cultivo no Brasil chega a aproximadamente um milhão de hectares, sendo essas duas regiões responsáveis por cerca de $90 \%$ da área cultivada total, além de ser uma das principais fontes de proteína para as famílias dessas regiões (SANTOS et al., 2017).

Geralmente, no Norte e Nordeste, o feijão caupi é cultivado em sistema de consócio junto com o milho (Zea mays L.) e pode ser colhido tanto seco como verde (BLANCO et al., 2011). O milho vem sendo utilizado em consórcios, devido ao seu metabolismo de fixação de carbono $(\mathrm{C} 4)$, porte alto e rápido crescimento inicial (KAPPES \& ZANCANARO, 2015).

O milho (Zea mays L.) é uma das mais importantes culturas, tanto para o agronegócio quanto para o agricultor familiar. Sua ampla utilização na indústria, como processados, consumo in natura e alimentação animal o torna um dos cereais de maior área plantada no Brasil, chegando a produzir 14,5 milhões de toneladas de grãos em 2012 (CHIEZA et al., 2017). O consórcio de culturas, cultivo múltiplo ou policultivo se dá pelo plantio de diferentes espécies em uma mesma área e no mesmo período de tempo, sendo estas espécies de diferentes morfologia e ciclo de vida (KAPPES \& ZANCANARO, 2015; DE ARAÚJO et al., 2016).

Há diversos benefícios em adotar o sistema consorciado, DE SOUZA et al. (2015) relatam que pode haver melhorias no uso da água, diminuição dos custos, melhor uso da terra, além de melhor aproveitamento da mão de obra, proteção do solo e menor risco de perda de produção. Nesse tipo de plantio, as espécies competem por água, luz e nutrientes, dessa forma, para que uma cultura não prejudique o desenvolvimento da outra, é necessário estabelecer uma população total de plantas adequadas, estudando a densidade e o espaçamento que essas plantas devem permanecer na área, através da análise de diferentes arranjos populacionais (SANTOS et al., 2016).

Em relação à produção do feijão caupi, a demanda pelas vagens e grãos verdes está em ritmo de crescimento, diminuindo a relação com a demanda para grãos secos, que historicamente foi a principal finalidade da produção. Para conseguir atender esse mercado crescente deve-se ter em mente o estádio fenológico da cultura para saber o período em que se tem a colheita das vagens verdes, sendo o período ideal de colheita quando as vagens atingirem entre $60 \mathrm{e}$ 
70\% de umidade (MENDONÇA et al., 2015).

Nesse sentido, objetivou-se com esse trabalho avaliar a produtividade de feijão caupi em vagens e grãos verdes em função dos sistemas de consórcio com o milho e da colheita parcelada.

\section{MATERIAL E MÉTODOS}

O experimento foi realizado no período de 10 de junho a 16 de setembro de 2016 na área experimental do Centro de Ciências Agrárias e da Biodiversidade (CCAB) da Universidade Federal do Cariri (UFCA), situada no município de Crato, Ceará, com as coordenadas geográficas 7014'49"S, 39²2'05"W e 413 metros de altitude. O clima, segundo a classificação de Köeppen é Aw', considerado tropical úmido, com inverno característico seco, com estação chuvosa presente de novembro a abril e estação seca de maio a outubro, no inverno. As precipitações geralmente são superiores a $750 \mathrm{~mm}$ anuais nas regiões de clima Aw', sendo encontrado esse clima no litoral e serras do Ceará (EMBRAPA, 2016).

O solo da área experimental foi classificado como Argissolo Vermelho Amarelo, de textura arenosa, conforme classificação de solos de média intensidade da FUNCEME (2012). A constituição química na camada de $0-20 \mathrm{~cm}$ foi: $\mathrm{pH}(1: 2,5$ $\mathrm{H} 2 \mathrm{O}$ ): 6,0; $\mathrm{P}$ (melich-1): 3,0 $\mathrm{mg} \mathrm{dm}^{-3}$; K: 1,27 mmolc dm${ }^{-3}$; Ca: 5,0 mmolc dm ${ }^{-3}$; $\mathrm{Mg}$ : $6,0 \mathrm{mmolc} \mathrm{dm}^{-3}$; CTC: $35,4 \mathrm{mmolc} \mathrm{dm}^{-3}$ e V (\%): 53.

O delineamento experimental utilizado foi em blocos casualizados em esquema fatorial $5 \times 4$, constando de quatro repetições. O primeiro fator analisado foi o sistema de consórcio do feijão com o milho (C1, C2, C3, C4 e C5) e o segundo foi a colheita parcelada (1를 $2^{a}, 3^{\underline{a}}$ e $4^{a}$ colheita).

Os sistemas de consórcio avaliados foram:

- C1 - Fileiras intercaladas de milho e feijão, com as fileiras de feijão estando espaçadas a $0,8 \mathrm{~m}$ uma da outra. Foram semeadas 7 sementes por metro de feijão, totalizando 87500 sementes por hectare.

- C2 - Fileiras intercaladas de milho e feijão, com as fileiras de feijão estando espaçadas a 1,2 m uma da outra. Foram semeadas 10,5 sementes por metro de feijão, totalizando 87500 sementes por hectare.

- C3 - Fileiras de milho espaçadas a 1,2 m e intercaladas com duas fileiras de feijão, espaçadas a 0,6 m uma da outra. Foram semeadas 5,25 sementes por metro de feijão, totalizando 87500 sementes por hectare.

- C4 - Fileiras de milho espaçadas a 1,6 m e intercaladas com duas fileiras de feijão, espaçadas a 0,8 m uma da outra. Foram semeadas 7 sementes por metro de feijão, totalizando 87500 sementes por hectare.

- C5 - Fileiras de milho espaçadas a 1,6 m e intercaladas com três fileiras de feijão, com espaçadas a 0,53 m uma da outra. Foram semeadas 4,64 sementes por metro de feijão, totalizando 87500 sementes por hectare.

Em todos os sistemas, procurou-se manter a mesma quantidade de sementes por hectare (87.500), alterando apenas o espaçamento entre plantas na fileira de semeadura, em função das alterações nos espalamentos entre fileiras pertinentes a cada sistema de consórcio.

Foi avaliada a colheita parcelada em função da maturação desuniforme das vagens de feijão caupi, fato essencial para a colheita das vagens verdes. As colheitas foram realizadas aos 63, 68, 77 e 85 dias após a semeadura (DAS), para a $1^{a}, 2^{a}, 3^{a}$ e $4^{\underline{a}}$ colheitas, respectivamente. Cada parcela experimental tinha quatro metros de comprimento por três de largura $\left(12 \mathrm{~m}^{2}\right)$, sendo avaliado dois metros por fileiras de feijão na parte central da parcela. 
Para a cultura do feijão não foi realizada adubação de fundação no momento da semeadura que foi realizada no dia 10 de junho de 2016, com as únicas práticas realizadas sendo a aplicação de óleo de neem com detergente neutro a $1 \%(\mathrm{v} / \mathrm{v})$ aos 15 e 30 DAS para controle de mosca branca e pulgão. Também foi realizada a capina manual aos 25 DAS para o controle de plantas daninhas.

A cultura foi irrigada por sistema de microaspersão com as fileiras de aspersores espaçadas a $3 \mathrm{~m}$, com distância entre os aspersores na linha de $4 \mathrm{~m}$. Cada aspersor possui vazão média de $80 \mathrm{~L} \mathrm{~h}^{-1}$. O turno de rega foi diário por um período de uma hora, totalizando uma lâmina diária de irrigação de 6,67 mm.

As variáveis analisadas foram o número de grãos por vagem e de vagens por planta, o comprimento das vagens, a massa de cem grãos e a produtividade de vagens e de grãos verdes. Os dados foram tabulados e submetidos à análise de variância e ao teste de comparação de médias de Tukey a $5 \%$ de probabilidade, utilizando-se o programa estatístico SISVAR 5.3 (FERREIRA, 2010).

\section{RESULTADOS E DISCUSSÃO}

De acordo com a análise de variância dos dados encontrados no presente trabalho (Tabela 1), para o fator Consórcio, o NG/V não foi significativo pelo teste $F$, já NV/P e CV foram significativos a 1 e $5 \%$, respectivamente. No fator Colheita Parcelada, NG/V, NV/P e CV foram significativos a 1\%. Na interação entre os dois fatores $(C \times P)$, nenhuma das variáveis obteve significância.

Dentre os consórcios, o C3 foi o que apresentou melhores resultados, seguidos por C5 e C4, respectivamente. Para NG/V, não houve diferença estatística entre os tratamentos, porém o C3 apresentou maior NG/V em relação a $\mathrm{C} 1$ e $\mathrm{C} 4$. Para NV/P, o C3 obteve uma média de 4,92, similar ao C5 $(3,92)$ e superior aos outros consórcios. Para CV, o C3 apresentou melhor resultado, seguido de C4, C5 e C2 que foram intermediários, enquanto o $\mathrm{C} 1$ obteve a menor média.

VIEGAS NETO et al. (2012), avaliando o consórcio entre feijão comum, cultivar BRSMG pioneiro, e milho pipoca, em diferentes arranjos de plantas também não encontraram diferenças significativas entre o número de grãos por vagem, assim como SANTOS et al. (2016), avaliando o desempenho do feijão-caupi e milho BRS Caatingueiro consorciados em diferentes densidades populacionais e arranjos de plantas, não encontraram efeito significatico para número de grãos por vagem e número de vagens por planta, explicando que esses resultados foram obtidos através da pouca influência do ambiente sobre essas características.

Entretanto, para o número de vagens por planta, DE SOUZA et al. (2014) avaliando doses de nitrogênio e efeito da população de plantas sobre o crescimento e produção da cultivar de feijoeiro comum, cultivar IPR Tangará, obtiveram resultados semelhantes ao deste trabalho, explicando que o aumento populacional aumenta a competição entre as plantas, reduzindo o número de vagens por planta.

Em relação ao comprimento de vagem, SOUSA et al. (2015), avaliando genótipos de feijão caupi para a seleção dos melhores para o mercado de vagens e grãos verdes, encontraram uma média geral de $22,14 \mathrm{~cm}$, valor acima do encontrado na maior média desse trabalho (19,3 cm, no tratamento C3), podendo ser explicado através da interferência do consórcio. Em relação à colheita parcelada (Tabela 1), a primeira e segunda colheitas, apresentaram resultados semelhantes, com maior NG/V e CV, indicando melhor desenvolvimento das vagens oriundas das primeiras flores, porém com menor NV/P do que as últimas colheitas (Colheita 3 e 4).

Estes resultados podem ser explicados pelo fato do feijão emitir poucas AGRARIAN ACADEMY, Centro Científico Conhecer - Goiânia, v.4, n.7; p.249 2017 
flores no início do período reprodutivo, assim, ocorre maior acúmulo de fotoasssimilados nos grãos, produzindo vagens maiores e com maior número de grãos. Com o decorrer do desenvolvimento, emite maior número de flores e consequentemente maior número de vagens, ocorrendo uma maior distribuição dos fotoassimilidos entres essas vagens e assim, diminuindo o comprimento das vagens e o número de grãos por vagem. LOCATELLI et al. (2014) encontraram resultados semelhantes, explicando que tem uma relação direta destas características com a fonte dreno.

TABELA 1. Síntese da análise de variância e do teste de médias para o número de grãos por vagem (NG/V), número de vagens por planta (NV/P) e comprimento da vagem (CV).

Fontes de Variação

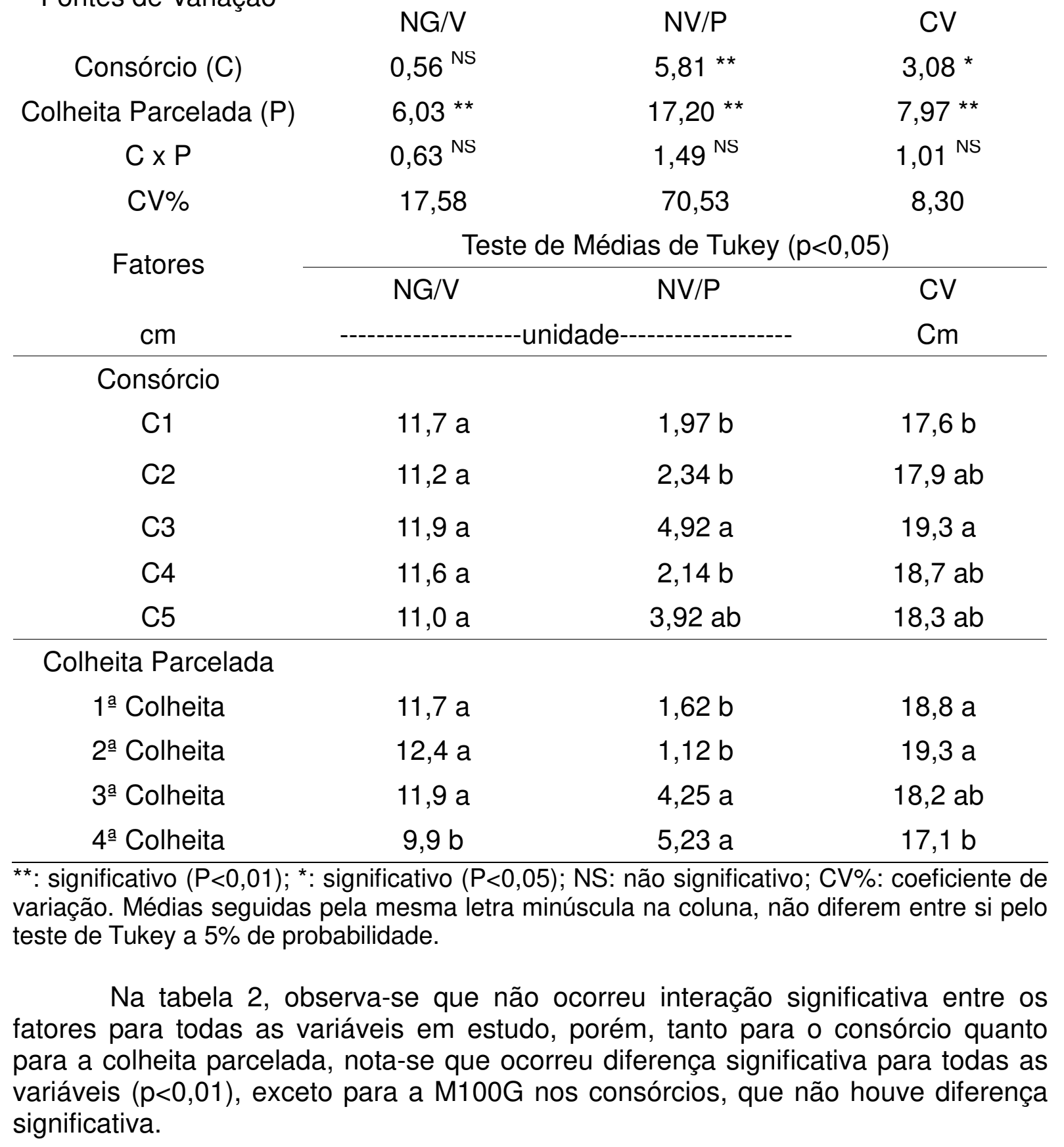


TABELA 2. Síntese da análise de variância e do teste de médias para a massa de cem grãos (M100G), a produtividade de vagens verdes (PVV) e a produtividade de grãos verdes (PGV).

Fontes de Variação

\begin{tabular}{|c|c|c|c|}
\hline & $M 1000$ & PVY & DCy \\
\hline Consórcio (C) & $0,72^{\mathrm{NS}}$ & $9,81 * *$ & 7,20 ** \\
\hline Colheita Parcelada $(P)$ & 19,60 ** & 8,93 ** & 9,95 ** \\
\hline$C \times P$ & $1,48^{N S}$ & $2,34^{\mathrm{NS}}$ & $2,04^{N S}$ \\
\hline \multirow[t]{2}{*}{ CV\% } & 17,89 & 64,72 & 71,18 \\
\hline & \multicolumn{3}{|c|}{ Teste de Médias de Tukey $(\mathrm{p}<0,05)$} \\
\hline \multirow[t]{2}{*}{ Fatores } & M100G & PVV & PGV \\
\hline & g & ---------- & ------- \\
\hline \multicolumn{4}{|l|}{ Consórcio } \\
\hline C1 & $30,3 \mathrm{a}$ & 764 bc & $429 \mathrm{bc}$ \\
\hline C2 & $27,7 \mathrm{a}$ & $666 \mathrm{c}$ & $360 \mathrm{c}$ \\
\hline C3 & $30,5 \mathrm{a}$ & $1892 \mathrm{a}$ & 989 a \\
\hline C4 & $28,9 \mathrm{a}$ & $684 \mathrm{c}$ & $393 \mathrm{bc}$ \\
\hline $\mathrm{C} 5$ & $29,5 \mathrm{a}$ & $1447 \mathrm{ab}$ & $808 \mathrm{ab}$ \\
\hline \multicolumn{4}{|l|}{ Colheita Parcelada } \\
\hline $1^{\text {a }}$ Colheita & 34,3 a & $811 \mathrm{~b}$ & $386 \mathrm{~b}$ \\
\hline $2^{\mathrm{a}}$ Colheita & $33,4 \mathrm{a}$ & $573 \mathrm{~b}$ & $291 \mathrm{~b}$ \\
\hline $3^{a}$ Colheita & $25,6 \mathrm{~b}$ & $1444 \mathrm{a}$ & $849 \mathrm{a}$ \\
\hline 4ㄹ Colheita & $24,2 \mathrm{~b}$ & $1535 \mathrm{a}$ & $856 \mathrm{a}$ \\
\hline
\end{tabular}

SANTOS et al. (2016) não encontraram diferença significativa, o que coincide com o presente trabalho. VIEGAS NETO et al. (2012) trabalhando com o consórcio entre milho pipoca e feijão comum e avaliando os diferentes arranjos de plantas também não encontraram diferenças significativas, sendo explicado no seu trabalho que o processo fisiológico da semente, como a massa do grão, não se alteram com os diferentes sistemas de cultivo, sendo outros fatores responsáveis pela redução da produtividade.

Com relação à produtividade de vagens e grãos verdes (tabela 2), o sistema de consórcio $\mathrm{C} 3$ obteve as melhores médias, sendo semelhante estatisticamente ao C5, com C2 e C4 obtendo as menores produtividades. Observa-se que nos sistemas de consórcio estudados, os que apresentaram maior produtividade (C3 e C5) foram os que utilizaram o menor número de sementes por metro, mantendo as plantas mais distantes na fileira de semeadura, com maior aproveitamento dos recursos naturais. Este comportamento ocorre, pois segundo BEZERRA et al. (2012), o adensamento das plantas tem reflexos negativos na produtividade em função da 
redução no número de ramos laterais e gemas reprodutivas.

Ao analisar a Tabela 2, observa-se que, para a colheita parcelada, as duas primeiras colheitas apresentaram melhor desenvolvimento dos grãos, assim como ocorreu para as variáveis da Tabela 1 em relação às vagens, verificado pela maior massa de cem grãos, porém em contrapartida, a produtividade de vagens e grãos verdes foi inferior às colheitas 3 e 4 . Esses resultados são semelhantes aos resultados anteriores, visto que é uma relação de produção, com as vagens de melhor qualidade sendo obtidas nas primeiras colheitas, e as maiores produtividades nas últimas.

\section{CONCLUSÕES}

Os sistemas de consórcio C3 e C5 apresentram os melhores resultados de produção do feijão caupi consorciado com o milho.

As colheitas 3 e 4, realizadas aos 77 e 85 dias após a semeadura, apresentaram os melhores rendimentos produtivos, porém a primeira e a segunda colheita propiciaram vagens e grãos maiores, sendo mais atraentes para o consumo verde.

\section{REFERÊNCIAS}

BEZERRA, A. DE C.; DE ALCÂNTRA NETO, F., DAS NEVES, A. C.; MAGGIONI, K. Comportamento morfoagronômico de feijão-caupi, cv. BRS Guariba, sob diferentes densidades de plantas. Revista de Ciências Agrárias Amazonian Journal of Agricultural and Environmental Sciences, v. 55, n. 3, p. 184-189, 2012. Disponível em: < http://doi.editoracubo.com.br/10.4322/rca.2012.059 >

BLANCO, F. F.; CARDOSO, M. J.; FREIRE FILHO, F. R.; VELOSO, M. E. DA C.; NOGUEIRA, C. C. P.; DIAS, N. DA S. Milho verde e feijão-caupi cultivados em consórcio sob diferentes lâminas de irrigação e doses de fósforo. Pesquisa Agropecuária Brasileira, v. 46, n. 5, p. 524-530, 2011. Disponível em: < https://seer.sct.embrapa.br/index.php/pab/article/view/10052/6351>

CHIEZA, E. D.; GUERRA, J. G. M.; ARAÚJO, E. DA S.; ESPÍNDOLA, J. A.; FERNANDES, R. C. Produção e aspectos econômicos de milho consorciado com Crotalária juncea L. em diferentes intervalos de semeadura, sob manejo orgânico. Revista Ceres, v. 64, n. 2, p. 189-196, 2017. Disponível em: < http://www.ceres.ufv.br/ojs/index.php/ceres/article/download/1770/2312> DOI: 10.1590/0034-737X201764020012

DE ARaÚJo, A. C.; ALOUfa, M. A. I.; DA SILVA, A. J. N.; DE ARAÚJO, A. C. Competição interespecífica e viabilidade econômica do consórcio gergelim-feijão caupi em sistema orgânico de cultivo em função de épocas de semeadura. Revista Brasileira de Agroecologia, v. 11, n. 2, p. 110-116, 2016. Disponível em: $<$ http://aba-

agroecologia.org.br/revistas/index.php/rbagroecologia/article/view/16138/12279>

DE SOUZA, A. B.; OLIVEIRA, D. P.; SILVA, C. A.; DE ANDRADE, M. J. B. Populações de plantas e doses de nitrogênio para o feijoeiro em sistema convencional. Bioscience Journal, v. 30, n. 4, p. 998-1006, 2014. Disponível em: < http://www.seer.ufu.br/index.php/biosciencejournal/article/view/21850/14744> 
DE SOUZA, L. S. B.; DE MOURA, M. S. B.; SEDIYAMA, G. C.; da SILVA, T. G. F. Requerimento hídrico e coeficiente de cultura do milho e feijão-caupi em sistemas exclusivo e consorciado. Revista Caatinga, v. 28, n. 4, p. 151-160, 2015. Disponível em: <http://www.redalyc.org/pdf/2371/237142689017.pdf>

EMBRAPA,

Clima.

Disponível

em:<

http://www.cnpf.embrapa.br/pesquisa/efb/clima.htm >. Acesso em: 23 de março de 2016.

FERREIRA, D. F. 2010. Sistema de análise SISVAR - de variância. Versão 5.3. Lavras-MG: UFLA.

FUNCEME - Fundação Cearense de Meteorologia e Recursos Hídricos . 2012. Levantamento de reconhecimento de média intensidade dos solos da Mesorregião do Sul Cearense / Fundação Cearense de Meteorologia e Recursos Hídricos. Fortaleza.

KAPPES, C.; ZANCANARO, L. Sistemas de consórcios de braquiária e de crotalárias com a cultura do milho. Revista Brasileira de Milho e Sorgo, v. 14, n. 2, p. 219-234, 2015. Disponível em: < http://rbms.cnpms.embrapa.br/index.php/ojs/article/view/615/pdf_421> DOI: http://dx.doi.org/10.18512/1980-6477/rbms.v14n2p219-234

LOCATELLI, V. DA E.; DE MEDEIROS, R. D.; SMIDERLE, O. L.; DE ALBUQUERQUE, J. DE A. A.; ARAÚJO, W. F.; DE SOUZA, K. T. S. Componentes de produção, produtividade e eficiência da irrigação do feijão-caupi no cerrado de Roraima. Revista Brasileira de Engenharia Agrícola e Ambiental, v. 18, n. 6, p. 574-580, 2014. Disponível em: < https://www.researchgate.net/profile/Wellington_Araujo5/publication/279120285_Co mponents_of_production_productivity_and_efficiency_of_irrigation_of_beancowpea_in_the_'Cerrado'_of_Roraima/links/56fbf25808ae1b40b8064016/Component s-of-production-productivity-and-efficiency-of-irrigation-of-bean-cowpea-in-the-

Cerrado-of-Roraima.pdf>

MENDONÇA, C. DE A.; BARROSO NETO, A. M.; BERTINI, C. H. C. DE M.; AMORIM, M. Q.; ARAÚJO, L. B. R. Caracterização fenológica associada a graus-dia em genótipos de feijão-caupi para produção de grãos verdes. Enciclopédia Biosfera, v. 11, n. 21, p. 485-496, 2015. Disponível em: < http://www.conhecer.org.br/enciclop/2015b/agrarias/Caracterizacao\%20fenologica.pd $\mathrm{f}>$

SANTOS, L. A. C.; SILVA, D. M. P.; OLIVEIRA, I. A.; PEREIRA, C. E.; CAMPOS, M. C. C. Crescimento de cultivares de feijão-caupi em solo de terra firme e várzea. Ambiência Guarapuava, v. 13, n. 1, p. 261-270, 2017. Disponível em: < http://revistas.unicentro.br/index.php/ambiencia/article/view/2376/pdf>

DOI:10.5935/ambiencia.2017.01.17nt

SANTOS, M. A.; BATISTA, P. S. C.; LOPES, M. F.; SILVA, M. G. DE M.; BERTO, A. L. F. Desempenho agronômico de milho consorciado com feijão-de-corda em diferentes populações e arranjos de plantas no semiárido mineiro. Revista Agroambiente, v. AGRARIAN ACADEMY, Centro Científico Conhecer - Goiânia, v.4, n.7; p.253 2017 
10, n. 3, p. 201-208, 2016. Disponível em: <http://revista.ufrr.br/agroambiente/article/view/3286/2065> DOI:10.18227/19828470ragro.v10i3.3286

SOUSA, J. L. M.; ROCHA, M. DE M.; E SILVA, K. J. D; DAS NEVES, A. C.; DE SOUSA, R. R. Potencial de genótipos de feijão-caupi para o mercado de vagens e grãos verdes. Pesquisa Agropecuária Brasileira, v. 50, n. 5, p. 392-398, 2015. Disponível em: < http://seer.sct.embrapa.br/index.php/pab/article/view/20501/12925> DOI: 10.1590/S0100-204X2015000500006

VIEGAS NETO, A. L.; HEINZ, R.; GONÇALVES, M. C.; CORREIA, A. M. P.; MOTA, L. H. S.; ARAÚJO, W. D. Milho pipoca consorciado com feijão em diferentes arranjos de plantas. Pesquisa Agropecuária Tropical, v. 42, n. 1, p. 28-33, 2012. Disponível em:< http://www.redalyc.org/pdf/2530/253023637008.pdf> 